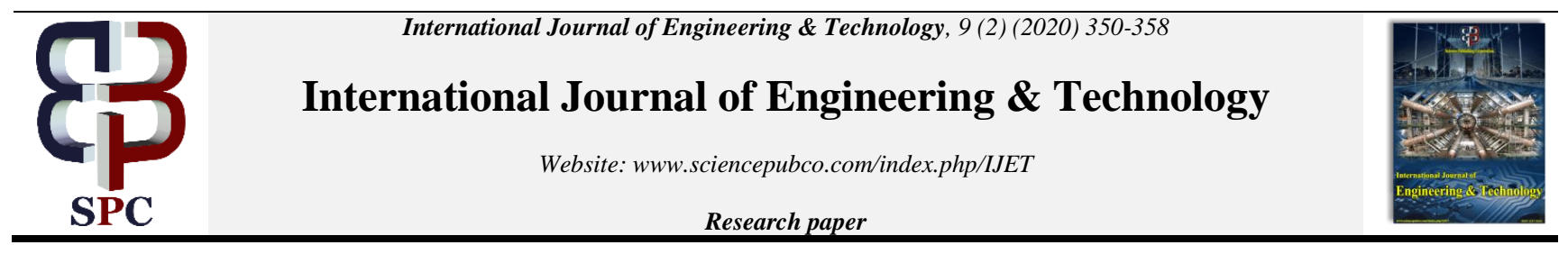

\title{
Reinforcement alternatives for beams under cyclic load
}

\author{
Louay A. Aboul-Nour ${ }^{1 *}$, Ragab S. Mahmoud ${ }^{1}$, Mahmoud A. Khater ${ }^{1}$, Nesma M. Moselhy ${ }^{2}$ \\ ${ }^{1}$ Associate Professor, Civil Engineering Department, College of Engineering, Zagazig University, Egypt \\ ${ }^{2}$ Structural Engineer, Civil Engineering Department, College of Engineering, Zagazig University, Egypt \\ *Corresponding author E-mail: engnesma2014.nm@gmail.com
}

\begin{abstract}
The major cause of concrete structures deterioration is steel corrosion. Consequently, this situation has led researchers to study and test other reinforcement alternatives that are noncorrosive in nature. Rapidly emerging developments in the field of material technology has led to the development of fiber reinforced polymers (FRP). This research focuses on the flexural behavior of carbon, glass, aramid, and basalt (CFRP, GFRP, AFRP, and BFRP) fiber reinforced polymers bars as alternatives to the traditional steel reinforcement in concrete. The study involves a nonlinear numerical finite element analysis of a simply supported reinforced concrete beams subjected to cyclic loading, where the ANSYS program is utilized. The numerical model verification is executed on the experimental beams for ensuring the efficiency of ma-terial models, cyclic loading and various elements. Hysteresis curves are produced for each beam and analyzed, where loads, deflections, and cracks propagation are inspected and discussed. The results reveal that, the full replacement of traditional steel bars with CFRP bars gives the greatest increase in the ultimate load capacity by $38.5 \%$. Also, other results are summarized in this paper.
\end{abstract}

Keywords: Finite Element Model; RC Beam; Flexural Behavior; Fiber Reinforced Polymer (FRP) Bars; Cyclic Load.

\section{Introduction}

It is well known that concrete is a building material with its relatively high compressive strength as compared to its low tensile strength. A concrete beam without any form of reinforcement cracks and fails when subjected to a relatively small load, the failure occurs suddenly and in a brittle manner. Over the years, traditional steel reinforcing bars [1] are used to resist the tension developed in concrete to extend the beams load carrying capacity, but concrete structures still face the problem of corrosion. Accordingly, researchers have embarked on studying the effectiveness of using alternatives to traditional steel bars. The development of fiber reinforced polymer (FRP) bars has rendered them to be a suitable choice as an alternative to traditional steel reinforcing bars [2]. Advantages of fiber reinforced polymers include excellent corrosion resistance, high tensile strength, and light in weight and consequently they have found acceptance in many construction applications [3 - 7]. Many researchers have studied fiber reinforced polymers (FRP) bars both experimentally and numerically, although the majority of them study beams under static loading while only a few study beams under dynamic or cyclic loading. Previous researches [8],[9] indicate that the performance and behavior of CFRP reinforced concrete beam is similar to that of the conventional steel reinforced concrete beam. The use of CFRP as reinforcement for concrete beams provide strength to the beam in the tension zone which indicates its efficiency to resisting flexure. Other researchers [10],[11] have studied the performance of GFRP beams, their findings indicate that the loads deflection curves were linear, Tension failure in the GFRP reinforcement was characterized by the rupture of GFRP bars at the region of maximum bending moment, and the use of small diameter bars exhibit better deflection properties than large diameter bars for the same reinforcement ratio. Also, higher beam stiffness is observed on increasing the reinforcement ratio, either by using more bars or larger diameter bars. Other researchers [12] have studied the flexural behavior of BFRP beams under repeated load. Results indicate that the total increase in deflections due to repeated loading increases as the number of cycles increase, where the greatest portion of this increase occurs in the later stages of the repeated loading. Also, adding low modulus BFRP rods to steel reinforcement decreases the mid span deflection at any load level and increases the ultimate deflection. As well others [13] have studied the flexural behaviors of hybrid concrete beams reinforced with BFRP bars and steel bars and beams performance with hybrid reinforcement of CFRP or GFRP bars and steel bars were studied [14], [15]. Comparative research between carbon and glass fiber reinforced polymers [16], [17] indicate that both GFRP and CFRP bars behaved linearly up to failure due to their linear characteristics as of their low modulus of elasticity as compared to that of steel. Deflection for the GFRP beams is larger than that of the CFRP beams due to the lower modulus of elasticity of the glass as compared to that of the carbon. Ultimate failure load achieved by the CFRP beams is higher than that of the GFRP beam due to the higher failure load of the CFRP bars than that of the GFRP bars. And The ultimate load for the beams reinforced by CFRP bars was larger than the ultimate load for the beams reinforced by GFRP bars. Effect of cyclic load on FRP reinforced beams was studied [18] and results detected that FRP reinforced concrete beams experiences better performance under repeated loading than those beams reinforced with conventional steel. Other type of FRP reinforcement is aramid fiber reinforced polymers (AFRP) which has been used by some researches [19 - 22]. Some researches discussed the replacement of traditional steel bars with one or two types of FRP bars under the effect of cyclic load for reinforced concrete beams. However, no researches handled replacement of steel bars with more than three types of FRP reinforcing 
bars and made a comparison between each other and between steel reinforcement for RC beams subjected to cyclic load. This research paper studies the structural flexural behavior of four different fiber reinforced materials used in reinforcing concrete beams (carbon, glass, aramid, and basalt) when subjected to cyclic loading. The results are compared to each other and to those of a beam with traditional steel reinforced beam.

\section{Validation of ANSYS models}

The purpose of this validation is to examine the ANSYS results and verify performance of ANSYS program in applying cyclic load from R. Vidya Sagar [23] literature as shown in Figure 1 and FRP reinforcement from Aly Abdel Zaher [16] literature as shown in Figure 2, by comparing the numerical results with the experimental ones as shown in Figure 3, it can be concluded that analysis using ANSYS program proved the efficiency of different element (3D SOLID65 for concrete, 3D LINK180 for reinforcement and 3D SOLID185 for loading and support plates) and material modelling in addition to the stepwise cyclic loading used. As well obtained the same trend of the experimental work results with good accuracy.

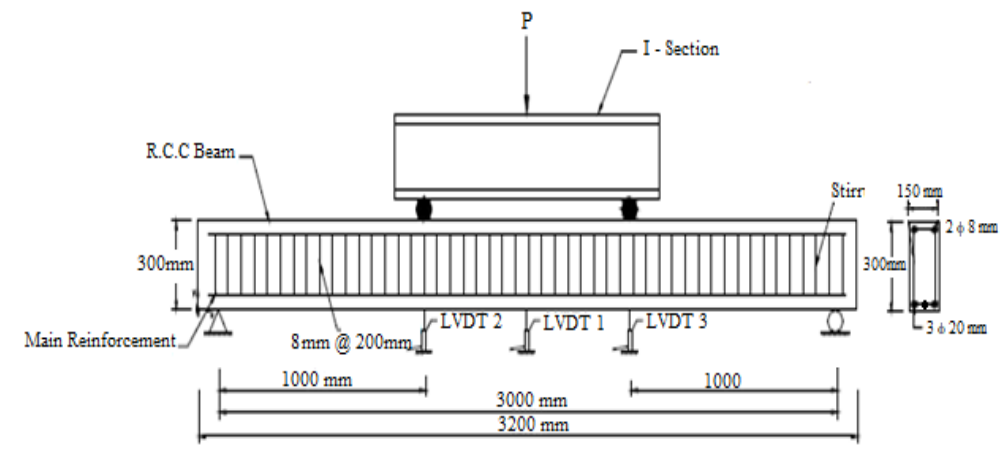

Fig. 1: Details of Verified Experimental Beam Tested by R. Vidya Sagar Et Al. [23].

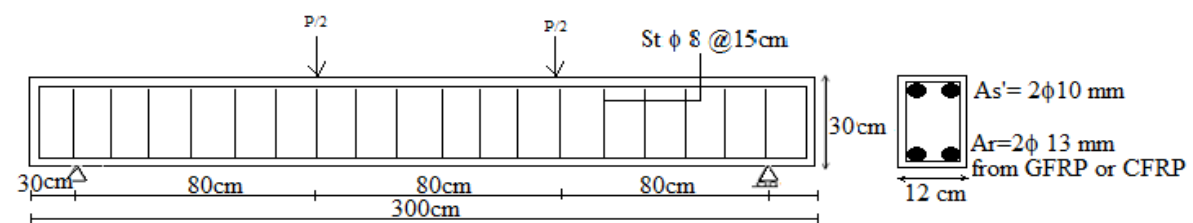

Fig. 2: Details of Verified Experimental Beam Tested by Aly Abdel Zaher Et Al. [24].
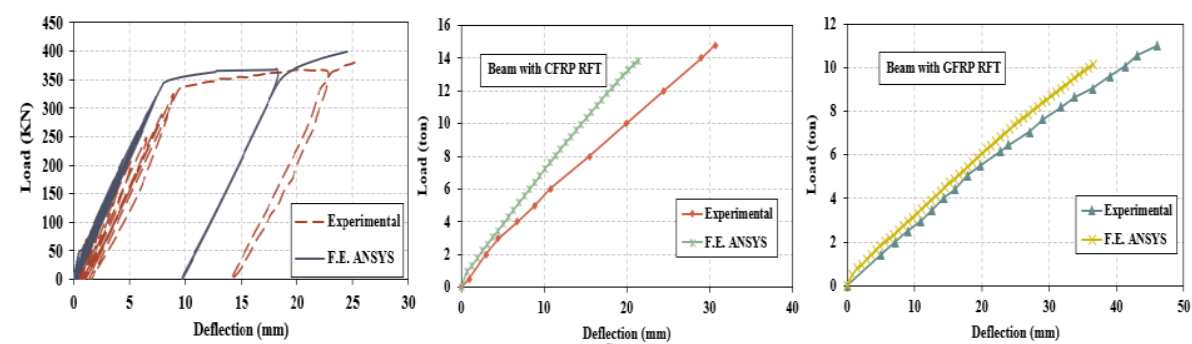

Fig. 3: Load Deflection Curve (FE VS Experimental) A) Beam (LL3) [23]; B) Beam (Dc12) [16]; C) Beam (Dg12) [16].

\section{Developed model details and numerical representation}

A parametric study was executed using the developed FE model to investigate the influence of the replacement of the traditional steel bars with FRP bars and the effect of different FRP types used. All beams are simply supported over a span of 6000 mm with a rectangular crosssection of $250 \mathrm{~mm}$ wide, and $550 \mathrm{~mm}$ total depth and loaded by two concentrated loads at the middle third where the distance between load and support is $2000 \mathrm{~mm}$. The longitudinal reinforcement consists of eight $18 \mathrm{~mm}$ diameter bars on the tension side, and four $10 \mathrm{~mm}$ diameter bars on the compression side. The transversal shear reinforcement consists of two leg stirrups of $10 \mathrm{~mm}$ diameter with a spacing of $100 \mathrm{~mm}$ as shown in Figure 4.
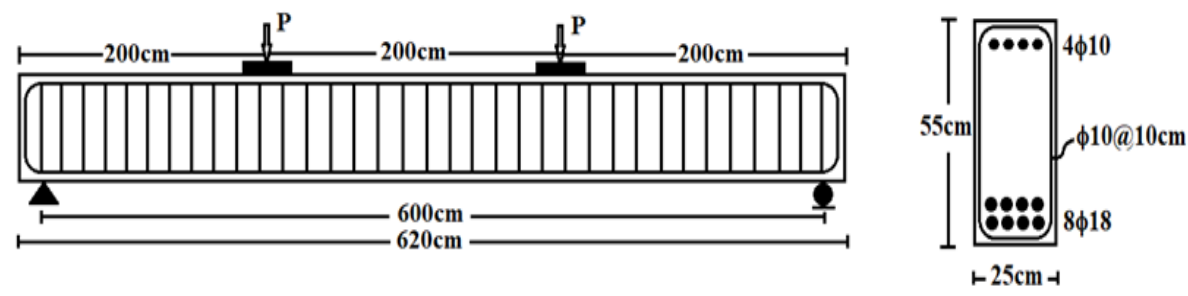

Fig. 4: Geometry, Reinforcement and Loading Details.

Taking advantage of the symmetry in two planes, only a quarter of the full beam is considered in modelling using ANSYS as shown in Figure 5 which facilitates the solution by finite element. All nodes located on the planes of symmetry are restricted from movement in the direction perpendicular to that plane for proper analysis. 


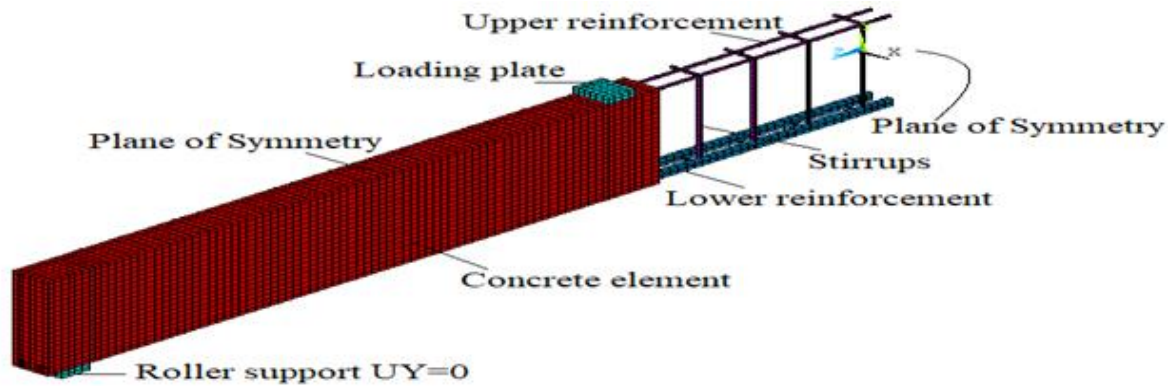

Fig. 5: Quarter Beam Numerical Modelling (Concrete \& Reinforcement).

\subsection{Model reinforcement}

Five reinforced concrete beams are studied in this paper. One beam reinforced with traditional steel bars and four beams reinforced with different types of fiber reinforced polymer bars include carbon fiber, aramid fiber, basalt fiber and glass fiber. All beams have 8 $\phi 18$ mm as its main reinforcement with $10 \phi 10 \mathrm{~mm} / \mathrm{m}$ ' stirrups and top reinforcement of $4 \phi 10 \mathrm{~mm}$. The characteristics of the specimens are shown in Table 1.

Table 1: Reinforcement Characteristics of Models

\begin{tabular}{lcl}
\hline Beam ID & Tension Reinforcement & Compression Reinforcement \\
\hline STEEL & $8 \phi 18 \mathrm{~mm}$ (Steel Bars) & $4 \phi 10 \mathrm{~mm}$ (Steel Bars) \\
CFRP & $8 \phi 18 \mathrm{~mm}$ (CFRP Bars) & $4 \phi 10 \mathrm{~mm}$ (Steel Bars) \\
GFRP & $8 \phi 18 \mathrm{~mm}$ (GFRP Bars) & $4 \phi 10 \mathrm{~mm}$ (Steel Bars) \\
AFRP & $8 \phi 18 \mathrm{~mm}$ (AFRP Bars) & $4 \phi 10 \mathrm{~mm}$ (Steel Bars) \\
BFRP & $8 \phi 18 \mathrm{~mm}$ (BFRP Bars) & $4 \phi 10 \mathrm{~mm}$ (Steel Bars) \\
\hline
\end{tabular}

\subsection{Reinforcement material properties}

Material properties for concrete, steel and the four different types of FRP reinforcing bars (CFRP\& GFRP\&AFRP and BFRP) used in this study as presented in Table 2 .

Table 2: Nonlinear Material Properties

\begin{tabular}{llll}
\hline \multirow{2}{*}{ Material } & $\begin{array}{l}\text { Material Parameters } \\
\text { Elastic Modulus (E) }(\mathrm{MPa})\end{array}$ & Poisson Ratio $(\mathrm{v})$ & \multicolumn{1}{c}{ Elastic Modulus (E) (MPa) } \\
\hline Concrete & $30,925.6$ & 0.2 & $\mathrm{~F}_{\mathrm{CU}}=50$ (Compressive Strength) \\
Steel & 200,000 & 0.3 & $\mathrm{~F}_{\mathrm{Y}}=360$ (Yield Strength) \\
CFRP & 145,000 & 0.25 & $\mathrm{~F}_{\mathrm{U}}=1934$ (Ultimate Stress) \\
GFRP & 43,000 & 0.25 & $\mathrm{~F}_{\mathrm{U}}=744$ (Ultimate Stress) \\
AFRP & 72,000 & 0.25 & $\mathrm{~F}_{\mathrm{U}}=1120$ (Ultimate Stress) \\
BFRP & 58,000 & 0.25 & $\mathrm{~F}_{\mathrm{U}}=800$ (Ultimate Stress) \\
\hline
\end{tabular}

\subsection{Cyclic loading pattern}

Cyclic loading is applied to all simply supported reinforced concrete beam. The loading method in this study is a two-point loading at the middle third. The load is applied in small increments as usually recommended in testing concrete beams. The incremental cyclic loading follows the time load curve shown in Figure 6.

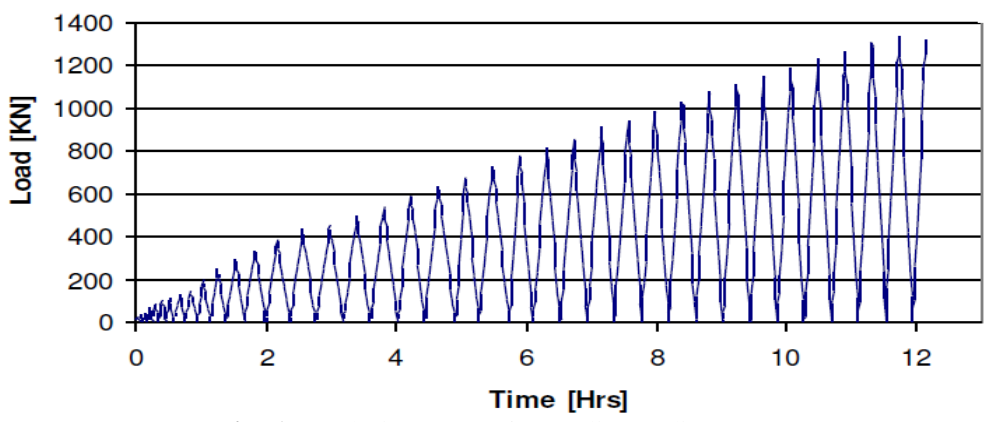

Fig. 6: Load Time Curve for Cyclic Loading [24].

\section{Numerical results and discussion}

\subsection{Hysteresis curves analysis}

The hysteresis curves for the studied beams are presented in Figure 7. Under cyclic loading, it could be observed that in the initial loading process, the hysteresis curves of the studied beams were generally a straight line with small residual deformation, indicating that the specimen is in an elastic state. Load cycles that do not exceed the load value which causes the initial crack exhibit no permeant deformation hence on unloading the specimen the beam fully retrieves the deformation that has occurred. Once the load cycle exceeds the cracking load, the initial crack occurs which is detected by the abrupt change in the loading slope of the load deflection curve, which indicates that plastic deformation occurs to the beam when it is unloaded. Following the load cycle causing the initial crack, all other load cycles lead to 
an increase in cracking which propagate till failure occurs. With every next load cycle the permanent plastic deformation increases when unloading the beam specimen. It is noticed that for the beam with traditional steel reinforcement there exists a wide loading cycle where deflection increases to a great extent with minimal or no increase in load which indicates the yield of the reinforcement. This behavior is absent in all beams that are reinforced with fiber reinforced polymers, where the load cycles are more condensed and overlap each other exhibiting sudden failure during the last cycle due to the brittle nature of the fiber polymer reinforcement used.
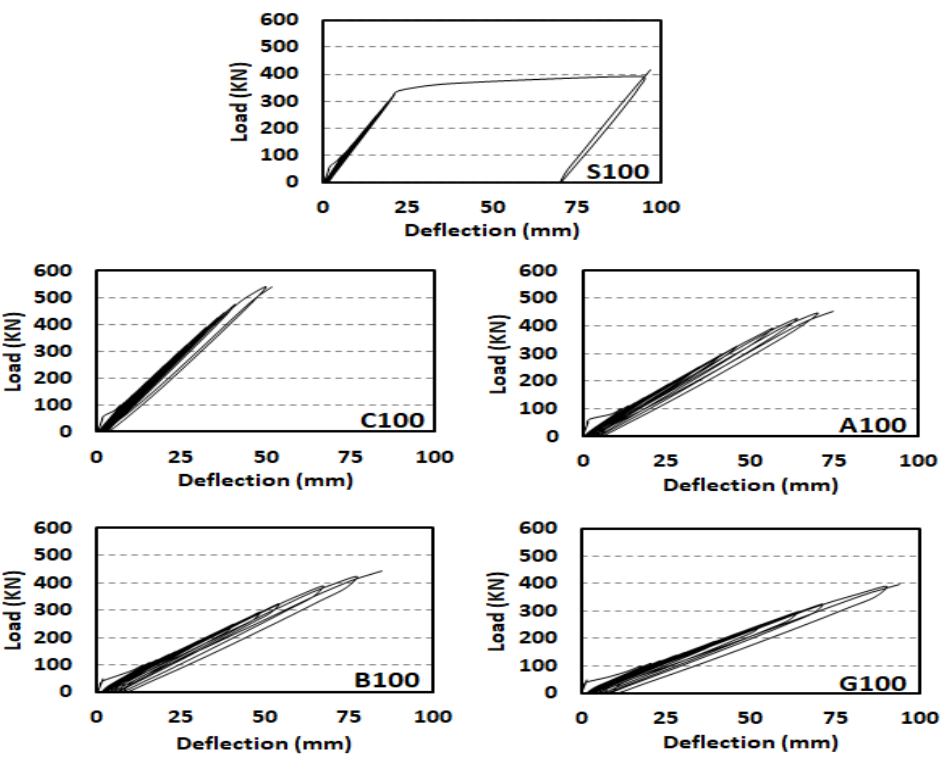

Fig. 7: Cyclic Load Deflection, Hysteresis Curves of Steel and FRP Beams.

\subsection{Prediction of maximum failure load and deflection from bar material properties}

The maximum load at failure is highly affected by the yield stress (in case of steel reinforced beams) or the ultimate stress (in case of carbon, aramid, basalt, and glass fiber reinforced beams) of the reinforcing material. Considering the steel reinforced beam failing at its yield stress, it is realized that at the beginning of the yield the load at failure recorded is $338 \mathrm{KN}$ while the carbon CFRP, aramid AFRP, basalt BFRP, and glass GFRP fiber reinforced beams failed at ultimate loads of 540, 451.3, 445, and 396.7 respectively. Comparing the failure load values with the yield of steel of $360 \mathrm{MPa}$ and the ultimate stress of 1934, 1120, 800, and $744 \mathrm{MPa}$ for carbon, aramid, basalt, and glass respectively it is realized that there is a high positive correlation $(\mathrm{R}=0.9617)$, where the higher the yield or ultimate stress of the reinforcement material the higher the failure load of the beam as shown in Figure 8.

The final value of deflection at failure is highly affected by the modulus of elasticity of the reinforcement material. Considering the steel reinforced beam failing at yield, it is realized that at the beginning of the yield it deflected $22.2 \mathrm{~mm}$ while the carbon CFRP, aramid AFRP, basalt BFRP, and glass GFRP fiber reinforced beams failed with deflections of 51.9, 74.6, 85.2, and 94.1 mm respectively. Comparing the deflection values with the elastic moduli of 200,000, 145,000, 72,000, 58,000, and 43,000 MPa of the steel, carbon, aramid, basalt, and glass respectively it is realized that there is a high negative correlation $(R=0.9929)$ where the higher the elastic modulus of the reinforcement material the lower the final deflection at failure as shown in Figure 9.

Accordingly, knowing the properties of the fiber reinforced polymer material used as bar reinforcement, it is possible to predict the ultimate load and deflection at failure using the following equations:

Predicting Failure Load:

$\mathrm{P}_{\text {failure }}=0.1212$ Fultyld +314.01

Predicting Deflection at Failure:

$D_{\text {failure }}=-0.4312 \mathrm{E}_{\text {material }}+110.27$

Where: $\mathrm{P}_{\text {failure }}$ is the maximum failure load in $(\mathrm{KN})$

Fult/yld is the yield or ultimate failure stress of the bar material in (MPa)

$\mathrm{D}_{\text {failure is }}$ the maximum deflection at failure in $(\mathrm{mm})$

$\mathrm{E}_{\text {material }}$ is the modulus of elasticity of the bar material (MPa) 


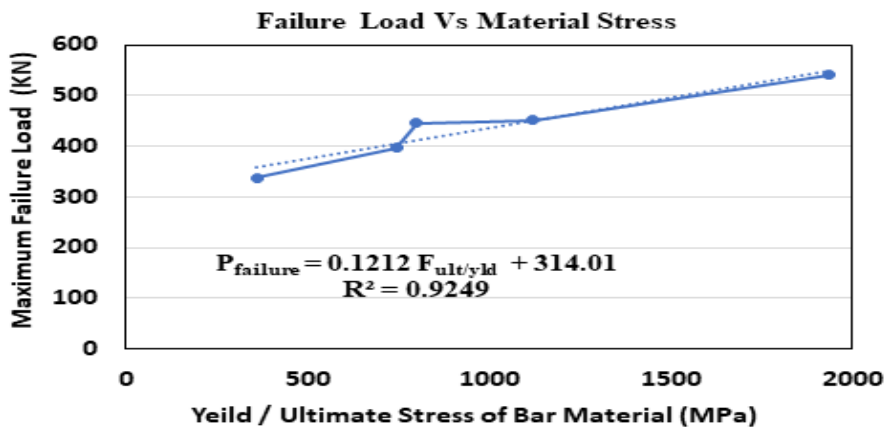

Fig. 8: Maximum Failure Load And Failure Stress of Bar Material.

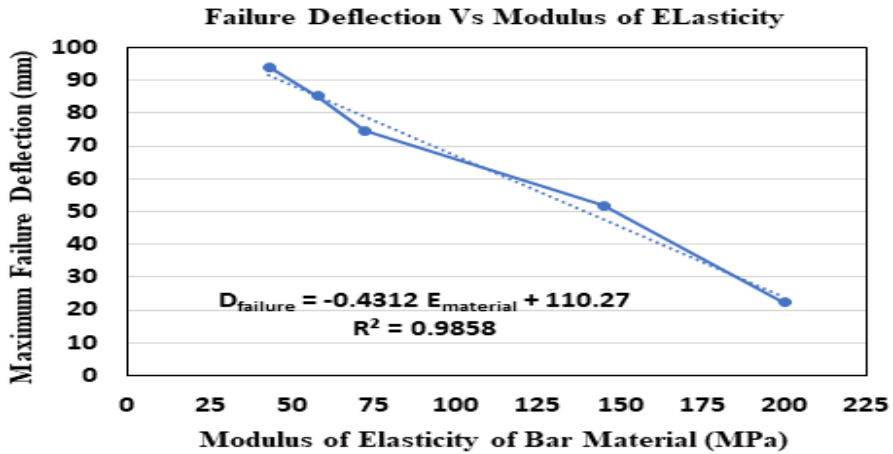

Fig. 9: Maximum Failure Deflection and Modulus of Elasticity of Bar Material.

\subsection{Development of permanent plastic deformation for cycles at unloading stages}

Application of cyclic loading on the beams causes an increase in the permanent deflection of the loaded beams. The permanent deflection in each cycle is calculated at the end of cycle (unloading stage) and presented in Table 3 and Figure 10. It is exhibited that the permanent plastic deformation follows an increasing trend for all beams, it can be noted that the steel beam has the lowest permanent deformation up to the cycle before the yield, after which the permanent deformation increases drastically (not shown in the figure) due to the yield of the steel reinforcement at failure hence indicating a highly ductile failure mode which is typical of steel reinforced beams. In the FRP (carbon, glass, aramid and basalt) beams, the permanent deformation increases in a similar manner, but at higher values than those exhibited by the steel reinforced beams. The permanent deformation values after the unloading of cycles are higher in value due to the brittle nature of the fiber reinforced polymer materials and the relatively low modulus of elasticity of fiber reinforced polymers (FRP) as compared to that of steel. It is also realized that carbon fiber bar beams failed after 16 cycles which is more than other beams, since it has the highest ultimate stress of $1934 \mathrm{MPa}$ as compared to the other bar materials. Hence allowing for higher load carrying capacity of the beam hence withstanding more cycles before failure. Also, the carbon fiber reinforced polymer (CFRP) beam exhibited the least permanent deformation (51.9 mm) after steel $(22.2 \mathrm{~mm})$ due to its high modulus of elasticity of $145000 \mathrm{MPa}$. The permanent deformation of aramid, basalt, and glass fiber reinforced polymer beams are $74.6,85.2$, and $94.1 \mathrm{~mm}$ respectively where their moduli of elasticity are 72000,58000 , and $43000 \mathrm{MPa}$ respectively. It is worth noting that the glass fiber reinforced polymer (GFRP) exhibited the greatest plastic deformation at failure of 94.1 $\mathrm{mm}$ which indicates better ductility and improved structural behavior although the glass fiber reinforced polymer as a material fails in a brittle nature when tested alone. The deflection is inversely proportional to the modulus of elasticity of the bar material as shown in Figure 9 .

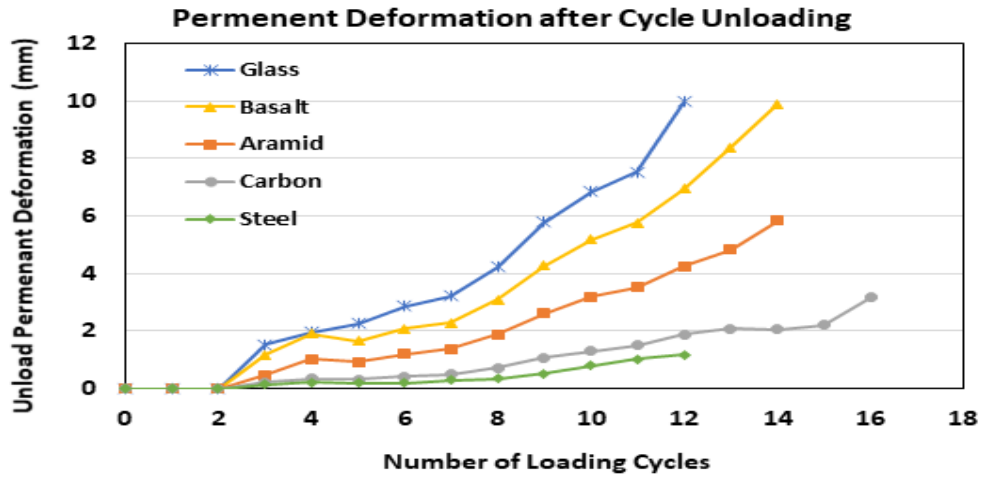

Fig. 10: Permeant Deformation After Each Cycle Unloaded.

Table 3: Permanent Deflection for Beams at Cycle Unloading

\begin{tabular}{|c|c|c|c|c|c|}
\hline \multirow{2}{*}{ Cycle Number } & \multicolumn{5}{|c|}{ Permanent Deflection at Unloading of Cycles } \\
\hline & Steel & Carbon & Aramid & Basalt & Glass \\
\hline 0 & 0.000 & 0.000 & 0.000 & 0.000 & 0.000 \\
\hline 1 & 0.000 & 0.000 & 0.000 & 0.000 & 0.000 \\
\hline 2 & 0.000 & 0.000 & 0.000 & 0.000 & 0.000 \\
\hline 3 & $0.153 *$ & $0.216 *$ & $0.460 *$ & $1.180 *$ & $1.525 *$ \\
\hline 4 & 0.224 & 0.356 & 1.024 & 1.897 & 1.967 \\
\hline
\end{tabular}




\begin{tabular}{|c|c|c|c|c|c|}
\hline 5 & 0.206 & 0.310 & 0.935 & 1.661 & 2.266 \\
\hline 6 & 0.206 & 0.430 & 1.198 & 2.081 & 2.860 \\
\hline 7 & 0.295 & 0.494 & 1.382 & 2.295 & 3.221 \\
\hline 8 & 0.344 & 0.717 & 1.870 & 3.089 & 4.236 \\
\hline 9 & 0.531 & 1.065 & 2.608 & 4.283 & 5.789 \\
\hline 10 & 0.811 & 1.312 & 3.205 & 5.175 & 6.834 \\
\hline 11 & 1.030 & 1.509 & 3.528 & 5.758 & 7.517 \\
\hline 12 & $1.171 * *$ & 1.892 & 4.244 & 6.951 & $9.976 * * *$ \\
\hline 13 & & 2.077 & 4.843 & 8.395 & \\
\hline 14 & & 2.064 & $5.846 * * *$ & $9.893 * * *$ & \\
\hline 15 & & 2.217 & & & \\
\hline 16 & & $3.169 * * *$ & & & \\
\hline
\end{tabular}

* Cycle of the initial crack

** Cycle where the steel reinforced beam yielded at failure

*** Cycle where the fiber reinforced beams failed at ultimate stress

\subsection{Development of maximum load for cycles}

The data of measured cycle load till failure and its deflection for the beams are presented in Table 4 and Figure 11 for all beams with the steel and fiber reinforcing bars. For the steel beam, the cyclic load increases gradually till it reaches a load of $325 \mathrm{KN}$ immediately before yield, then it is unloaded and during the next cycle yield occurs and the beam fails at a maximum load of $390 \mathrm{KN}$. On the other hand, FRP reinforced beams, fail at load values of $540,451.25,445$ and $396.7 \mathrm{KN}$ for carbon, aramid, basalt and glass beams respectively. These values explain that the complete replacement of traditional steel bars with carbon, aramid and basalt fiber reinforced polymer bars, leads to an increase in capacity of the beam by $38.5,15.7,14.1$ and $1.7 \%$ for carbon, aramid, basalt and glass beams respectively. This is due to the fact that the carbon, aramid, basalt, and glass fiber reinforced polymer bars possess ultimate failure stresses of 1934, 1120, 800, and $744 \mathrm{MPa}$ respectively which are much higher than the yield stress $360 \mathrm{MPa}$ of steel. Accordingly, higher ultimate failure stresses of the bar materials allow for higher beam carrying capacities, as shown by the carbon fiber reinforced polymer CFRP bars. Hence for strengthening purposes it is recommended to use stronger fiber reinforced polymer materials as an alternative reinforcement.

Table 4: Load Deflection at Cycle Load Peaks

\begin{tabular}{|c|c|c|c|c|c|}
\hline \multirow{2}{*}{ Cycle Load (KN) } & \multicolumn{5}{|c|}{ Maximum Cycle Deflection for Beams } \\
\hline & Steel & Carbon & Aramid & Basalt & Glass \\
\hline 0 & 0.00 & 0.00 & 0.00 & 0.00 & 0.00 \\
\hline 25 & 0.73 & 0.76 & 0.81 & 0.82 & 0.83 \\
\hline 50 & 1.45 & 1.52 & 1.62 & 1.64 & 1.66 \\
\hline 100 & 5.28 & 6.68 & 11.37 & 13.45 & 17.58 \\
\hline 110 & $6.14 *$ & $7.86 *$ & $13.70 *$ & $15.71 *$ & $20.59 *$ \\
\hline 120 & 6.96 & 8.84 & 15.54 & 17.95 & 23.55 \\
\hline 140 & 8.32 & 10.55 & 18.49 & 21.56 & 28.25 \\
\hline 150 & 9.04 & 11.50 & 20.08 & 23.52 & 30.77 \\
\hline 190 & 11.71 & 14.87 & 25.85 & 30.45 & 39.58 \\
\hline 250 & 15.75 & 20.00 & 34.67 & 40.75 & 53.13 \\
\hline 295 & 18.80 & 23.92 & 41.39 & 48.79 & 63.70 \\
\hline 325 & 20.89 & 26.57 & 46.01 & 54.39 & 71.31 \\
\hline 338 & 22.19 & 25.06 & 48.08 & 59.40 & 75.09 \\
\hline 390 & $94.14 * *$ & 32.37 & 56.60 & 67.54 & 90.14 \\
\hline 397 & --- & --- & --- & --- & $94.01 * * *$ \\
\hline 425 & --- & 35.75 & 58.50 & 77.64 & --- \\
\hline 445 & --- & 37.81 & 70.06 & $85.17 * * *$ & --- \\
\hline 451 & --- & --- & $74.61 * * *$ & --- & --- \\
\hline 475 & --- & 40.97 & --- & --- & --- \\
\hline 540 & --- & 50.12 & --- & --- & --- \\
\hline 540 & --- & $51.92 * * *$ & --- & --- & --- \\
\hline
\end{tabular}

* Cycle deflection of the initial crack

** Cycle deflection where the steel reinforced beam yielded at failure

*** Cycle deflection where the fiber reinforced beams failed at ultimate stress

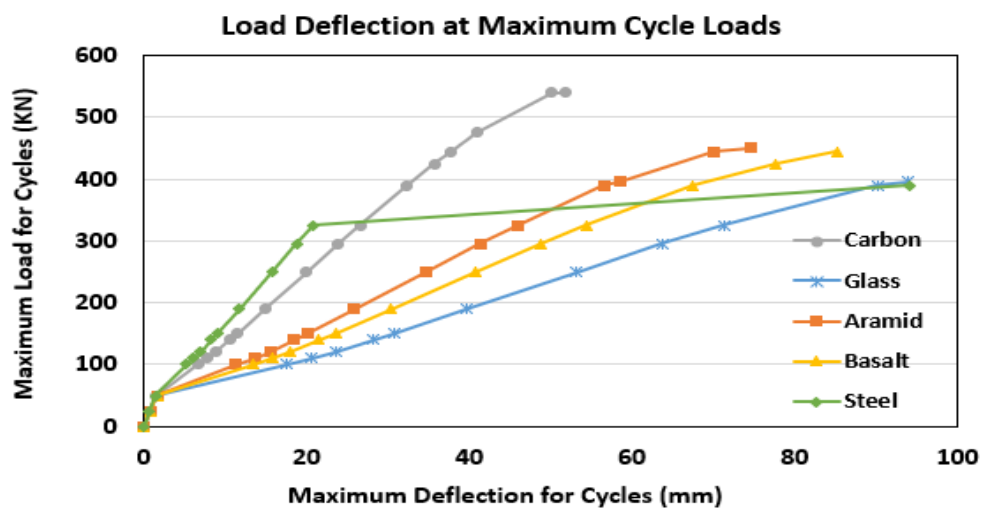

Fig. 11: Maximum Cycle Load for Various Bar Reinforced Beams. 
The cracks appear during the loading process. The location of cracks is observed during loading at each level till failure occurs as shown in Figure 12. For all beams, the initial tensile cracks begin in the third loading cycle and are located at mid-span. On successive cyclic loading of the beams the cracks widen and propagate upwards towards the compression zone, and in the meantime other new tension cracks appeared throughout the middle third and beyond, forming the typical toothlike pattern. The steel reinforced beam possessed the least number of cracks, with a major crack at midspan that widened, during the loading cycle in which yield of the steel reinforcement occurs. In contrast the FRP beams possessed an extensive number of cracks that increase and spread throughout the entire span of the beam with no well-defined toothlike nature, where the extensive cracking of FRP reinforced beams is due to the brittle nature of the fiber material that constitute the bars.

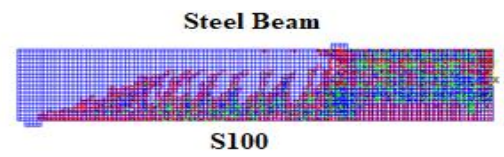

CFRP Beam
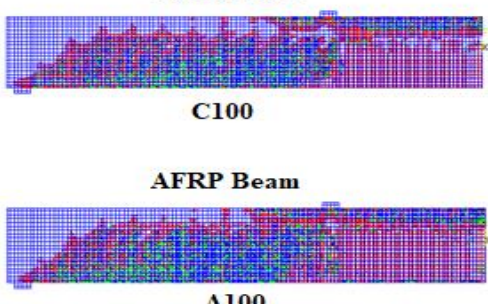

Fig. 12: Crack Propagation of Beams at Failure.

GFRP Beam

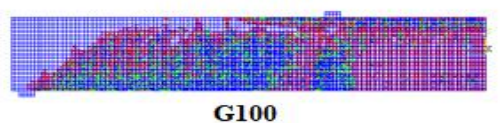

G100

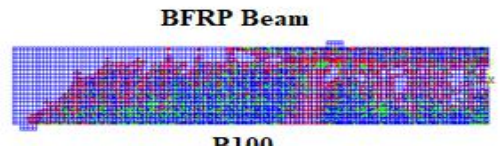

B100

\subsection{Concrete strains in beams}

The concrete strains on the concrete surface of the beams are presented in Figure 13, where for all beams the strain exceed the maximum strain value of 0.003 . Comparing the strain contours, it is realized that the strains are inversely proportional to the modulus of elasticity of the fiber where higher levels of strains occur in glass, basalt, aramid then carbon. The strain in concrete in the extreme top fiber of the fiber reinforced beams reached the maximum permissible value of 0.003 at value of load 295, 303, 325, and $459 \mathrm{KN}$ for glass, basalt, aramid, and carbon fiber bar respectively as compared to the load value of $338 \mathrm{KN}$ for the traditionally steel reinforced beam. Inspecting the values of load indicates that the strain of 0.003 in concrete is reached at lower values of load for the glass, basalt, and aramid fiber bar beams than for the steel bar beam indicating that lower modulus of elasticity allows for higher deflections. While for the carbon fiber bar beam the strain of 0.003 is reached at a load value of 459 which is much higher than that of the steel bar beams which is attributed to its modulus of elasticity that is more or less comparable to that of steel, hence less deflection is permitted during the loading process. The modulus of elasticity of the fiber attributes to both the deflection and the strain on the surface of the beam. In conclusion lower modulus of elasticity allows for higher strains and consequently higher deflections hence giving the beam a more ductile like nature when loaded to failure. Accordingly, for ductility purposes it is recommended to use a fiber material that has a lower modulus of elasticity. So, in order to improve the load carrying capacity and allow for favorable ductility it is required to use an alternative reinforcement that possesses high ultimate failure stresses and low elastic modulus, with a major aesthetic drawback of unpleasant extensive cracking occurring.
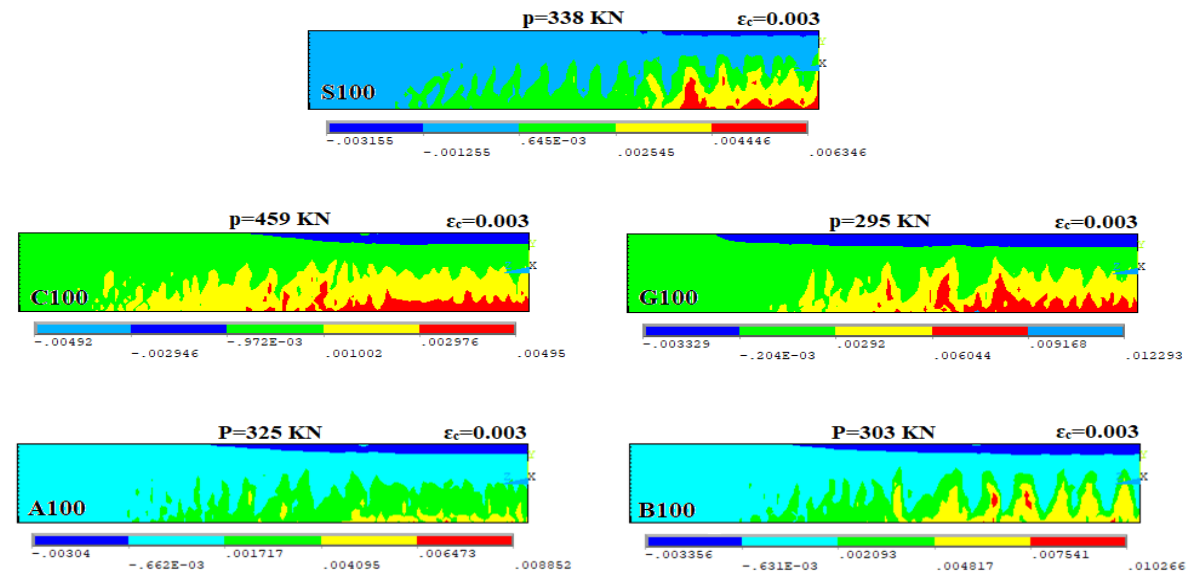

Fig. 13: Concrete Strains of Beams at Failure.

\subsection{Stresses in reinforcement at failure}

The distribution and development of the stresses in the reinforcement grid as shown in Figure 14 are assessed at the last available load case (time step) for steel reinforced beam S100 and fiber reinforced beams C100, A100, B100, and G100. Inspecting stress values in the reinforcement bars, it is realized that the stresses in the steel bars are higher than those stresses developing in the fiber polymer bars up to the third cycle at which the initial cracking occurs. This indicates that the steel bars stress instantaneously due to loading while the fiber bars stress in a more delayed manner in particular after the first crack occurs. After the first crack occurs the stresses in both the steel and fiber polymer bars are more of less comparable to each other until they reach the yield stress of steel $360 \mathrm{MPa}$, where the stresses in steel become constant due to yield, while the stresses in the fiber polymer bars develop and proceed to higher levels depending on the modulus of elasticity of the fiber material. The maximum stresses, located at the mid-span section, for fiber polymer bars are $638,519,500$ and 433.5 MPa for Carbon, Aramid, Basalt, and Glass respectively. All fiber reinforced polymer beams have exhibited higher reinforcement stresses 
as compared to that of the traditional steel reinforced beam. This is attributed to the substantial ultimate failure stresses of $1934,1120,800$, $744 \mathrm{MPa}$ for Carbon, Aramid, Basalt, and Glass fiber reinforcement respectively. Which are many folds higher than the yield stress 360 $\mathrm{MPa}$ of traditional steel reinforcement, therefore the carrying capacity of the beams is increased considerably, and accordingly the stresses in the fiber reinforced polymer bars are expected to reach higher values.
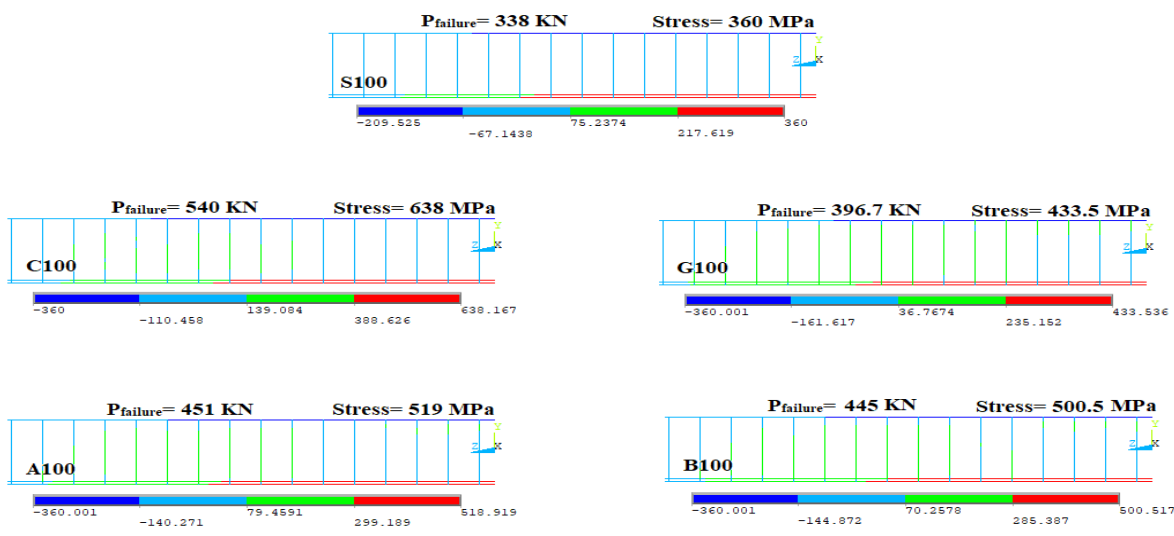

Fig. 14: Stresses in the Fiber Reinforced Polymer Bars at Failure.

\subsection{Load carrying capacity and deflection propagation}

Comparing the load carrying capacity (at failure) of the fiber reinforced beams with the traditional steel reinforced beam where the effect of strain hardening was taken into consideration. The load carrying capacity presented in Table 5 has increased by $38.5,15.6,14.1$, and $1.8 \%$ for Carbon, Aramid, Basalt, and Glass fiber bar beams respectively. On the contrary comparing the deflections at various levels of load it is realized that for loads within the elastic zone of the steel reinforcement (before yield), all fiber polymer beams showed increased deflections that are proportional to the elastic modulus of the fiber material. Immediately before yield (at a load of $338 \mathrm{KN}$ ) the steel reinforced beam deflected $22.19 \mathrm{~mm}$ whereas the Carbon, Aramid, Basalt, and Glass reinforced beams deflected 25.06, 48.08, 59.40, and $75.09 \mathrm{~mm}$ which consist of an increase in deflection of 13,117, 168, and 238\% respectively. This indicates that the polymer fiber reinforced beams exhibit extensive cracking at early loads after the initial crack Fig. 12 which may be aesthetically unacceptable. The traditional steel reinforced beam, cracks in a much less extensive pattern due to the high modulus of elasticity of steel. At the load level of $390 \mathrm{KN}$ after yield and considerable strain hardening of the steel reinforcement, the beam deflected $94.14 \mathrm{~mm}$ where the Carbon, Aramid, Basalt, and Glass fiber reinforced beams deflected 32.37, 56.60, 67.54, and $90.14 \mathrm{~mm}$, constituting a decrease in deflection of 66, 40, 28, and 4.2\% respectively. Indicating that the polymer fiber reinforcement is able to carry more loads and consequently stresses in fiber reinforcement increase. Finally, at failure and different levels of load, the deflection of Carbon, Aramid, Basalt, and Glass were recorded to be 51.92, 74.61, 85.17, and $94.01 \mathrm{~mm}$ which constitute an overall decrease in deflection of 45, 21, 10 and $0 \%$ respectively. Indicating the brittle nature of failure and loss of ductility of the beam.

Table 5: Deflection and Percent Change at Different Load Levels for Fiber Polymer Bars Beams

\begin{tabular}{|c|c|c|c|c|}
\hline \multirow{3}{*}{$\begin{array}{l}\text { Reinforcement Material (Elastic Modulus MPa) } \\
\text { Tradition Steel (200000 MPa) }\end{array}$} & \multicolumn{4}{|c|}{ Deflection $(\mathrm{mm})$ at Load Levels $(\mathrm{KN})$} \\
\hline & $\begin{array}{l}\text { At } 338 \mathrm{KN} \\
(\mathrm{mm})(\% \text { change })\end{array}$ & $\begin{array}{l}\text { At } 390 \mathrm{KN} \\
(\mathrm{mm})(\% \text { change })\end{array}$ & $\begin{array}{l}\text { At Failure } \\
(\mathrm{mm})(\% \text { change })\end{array}$ & $(\mathrm{KN})(\%$ change $)$ \\
\hline & 22.19 (Ref.) & 94.14 (Ref.) & 94.14 (Ref.) & 390 (Ref.) \\
\hline Carbon Fiber (145000 MPa) & $25.06(+13 \%)$ & $32.37(-66 \%)$ & $51.92(-45 \%)$ & $540(+38.5 \%)$ \\
\hline Aramid Fiber (72000 MPa) & $48.08(+117 \%)$ & $56.60(-40 \%)$ & $74.61(-21 \%)$ & $451(+15.6 \%)$ \\
\hline Basalt Fiber (58000 MPa) & $59.40(+168 \%)$ & $67.54(-28 \%)$ & $85.17(-10 \%)$ & $445(+14.1 \%)$ \\
\hline Glass Fiber (43000 MPa) & $75.09(+238 \%)$ & $90.14(-4.2 \%)$ & $94.01(0 \%)$ & $397(+1.80 \%)$ \\
\hline
\end{tabular}

\section{Conclusion}

1) Fiber polymer reinforcing bars may be used as an alternative to traditional steel reinforcement.

2) Under cyclic loading, mode of failure of the traditional steel beam (S100) is ductile with large yield stage, but for fiber reinforced polymers beams (C100, G100, A100, and B100), mode of failure becomes brittle depending on the modulus of elasticity of the fiber material.

3) The overall deflection of the beams reinforced with fiber polymer bars decreases by 45, 21, and 10\% for Carbon, Aramid, and Basalt bar beams respectively as compared with that recorded by the steel reinforced beams. Where the overall deflection of the glass bar beams is similar to that of the steel reinforced beams with negligible change.

4) The complete replacement of traditional steel bars with carbon, aramid, basalt and glass fiber reinforced polymer bars, leads to an increase in capacity of the beam by $38.5,15.7,14.1$ and $1.7 \%$ for carbon, aramid, basalt and glass beams respectively.

5) The higher the ultimate stress of the fiber material, the higher the ultimate failure load of the beams. Where the prediction of the failure load is possible for similar beam dimensions and loading details according to the proposed equation.

$\mathrm{P}_{\text {failure }}=0.1212 \mathrm{Fult}_{\mathrm{yld}}+314.01$

6) The higher the elastic modulus of the reinforcement material the lower the final deflection at failure. Where the prediction of the failure deflection is possible for similar beam dimensions and loading details according to the proposed equation.

$D_{\text {failure }}=-0.4312 E_{\text {material }}+110.27$ 
7) The steel reinforced beam possessed the least number of cracks, with a major crack at midspan which stays active during yield and strain hardening, while other cracks reside and become passive or dormant. In contrast the FRP beams, at early stages of loading, after the initial cracking of concrete, possessed an extensive number of cracks that increase and spread throughout the entire span of the beam where the modulus of elasticity is lower than that of steel in addition to the brittle nature of the fiber material of the bars.

8) The strains are inversely proportional to the modulus of elasticity of the fiber, so higher levels of strains occur in descending order for glass, basalt, aramid and carbon.

9) The maximum stresses recorded at the mid-span section were 638, 519, 500 and $433.5 \mathrm{MPa}$ for Carbon, Aramid, Basalt, and Glass respectively are much higher in value than the yield stress of steel $360 \mathrm{MPa}$ due to the much higher ultimate stress of the fiber material.

\section{References}

[1] Hakan Nordin, "Flexural Strengthening of Concrete Structures with Prestressed Near Surface Mounted CFRP Rods", licentiate thesis 2003:25, Lulea university of technology, Division of Structural Engineering, S-971 87 Lulea Sweden, (2003).

[2] ACI 440.1R-06. Guide for the Design and Construction of Structural Concrete reinforced with FRP Bars, Reported by ACI Committee 440, (2006).

[3] Williams B, Kodur V, Green M, Bisby L. "Fire endurance of fiber-reinforced polymer strengthened concrete T-beams", J. ACI Struct., Vol. 105, Issue 1, Jan./Feb. (2008), pp. 60-67. https://doi.org/10.14359/19069.

[4] R.A. Hawileh, M.Z. Naser "Thermal-stress analysis of RC beams reinforced with GFRP bars", Composites Part B: Engineering, Vol. 43, Issue 5, (2012), pp. 2135-2142, available online: https://doi.org/10.1016/j.compositesb.2012.03.004.

[5] M. Bazli, H. Ashrafi, A.V. Oskouei, "Experiments and probabilistic models of bond strength between GFRP bar and different types of concrete under aggressive environments", Constr. Build. Mater. Vol.148, (2017), pp. 429-443, available online: https://doi.org/10.1016/j.conbuildmat.2017.05.046.

[6] H. Ashrafi, M. Bazli, A. Vatani Oskouei, L. Bazli, "Effect of sequential exposure to UV radiation and water vapor condensation and extreme temperatures on the mechanical properties of GFRP bars", J. Compos. Constr., Vol.22, (2018), pp. 04017047-1- 04017047-17, available online: https://doi.org/10.1061/(ASCE)CC.1943-5614.0000828.

[7] Nayera Ahmed A. Mohamed, "Strength and Drift Capacity of GFRP Reinforced Concrete Shear Walls", Doctoral Thesis, Sherbrooke University, Canada, (2013).

[8] R N. M. Norazman, M. H. A. Boestamam, M. A. Yusof, "Carbon Fiber Reinforced Polymer (CFRP) as Reinforcement for Concrete Beam”, International Journal of Emerging Technology and Advanced Engineering, Vol. 3, Issue 2, February (2013), pp. 6-10, available online: http://citeseerx.ist.psu.edu/viewdoc/download?doi=10.1.1.413.5404\&rep=rep1\&type=pdf.

[9] Qusay W. Ahmed, Ali Laftah Abbas and Hafeth I. Naji, "Finite Element Simulation of Continuous FRP Reinforced Concrete Beams". Journal of Engineering and Applied Sciences, Vol. 14, (2019), pp. 6419-6424, available online: https://doi.org/10.36478/jeasci.2019.6419.6424.

[10] Maher A. Adam, M. Said, A. A. Mahmoud, A. S. Shanour, "Analytical and experimental flexural behavior of concrete beams reinforced with glass fiber reinforced polymers bars", Construction and Building Materials, Vol. 84, (2015), pp. 354-366, available online: https://doi.org/10.1016/j.conbuildmat.2015.03.057.

[11] S. El-Gamal. B. AbdulRahman. And B. Benmokrane. "Deflection Behavior of Concrete Beams Reinforced with Different Types of GFRP Bars", Proceedings of the 5th International Conference on FRP Composites in Civil Engineering, CICE 2010, (2011), pp. 279-282. https://doi.org/10.1007/978-3-642-17487-2 59.

[12] Mohmed M. Ahmed, Atif M. Abdel Hafez, Kamal A. Assaf, Abdel Kader A. Haridy, "Flexural Behavior of Basalt FRP RC Beams under Repeated Load", Journal of Engineering Sciences; Vol. 42, Issue 5, Sep. (2014), p1179.

[13] Wenjie Ge., Jiwen Zhang, Dafu Cao., Yongming Tu., "Flexural behaviors of hybrid concrete beams reinforced with BFRP bars and steel bars", Construction and Building Materials, Vol. 87, July (2015), pp. 28-37, available online: https://doi.org/10.1016/j.conbuildmat.2015.03.113.

[14] Jin Chen, "Performance of a transfer beam with hybrid reinforcement of CFRP bars and steel bars under reversed cyclic loading", Science and Engineering of Composite Materials, Vol.24(4), July (2017), available online: https://doi.org/10.1515/secm-2015-0035.

[15] Ahmed El Refai, Farid Abed, Abdullah Al-Rahmani, "Structural performance and serviceability of concrete beams reinforced with hybrid (GFRP and steel) bars", Construction and Building Materials, Vol. 96, 15 October (2015), pp. 518-529, available online: https://doi.org/10.1016/j.conbuildmat.2015.08.063.

[16] Abdel, A., Elsayed, Z., Ahmed, M.M., Salaheldin, H., \& Hassan, M.I., "Behavior of Beams Reinforced with Different Types of Bars from Glass Fiber Reinforced Polymer (GFRP), Carbon Fiber Reinforced Polymer (CFRP) and High Tensile Steel (HTS) Under Static Load", IOSR Journal of Mechanical and Civil Engineering (IOSR-JMCE), Vol. 12, Issue 4 Ver. V Jul. - Aug. (2015), pp. 66-97, available online: https://Doi:10.6084/M9.FIGSHARE.1517653.

[17] Rania Salih Mohammed, Zhou Fangyuan, "Numerical Investigation of the Behavior of Reinforced Concrete Beam Reinforced with FRP Bars", Civil Engineering Journal, Vol. 5, No. 11, (2019), pp. 2296-2308, available online: https://doi.org/10.28991/cej-2019-03091412.

[18] J.Karthick, Dr. K.Natarajan, and Ramachandran Murugan, "Cyclic Load Behaviour of RC T - Beams internally Reinforced with GFRP Reinforcements", International Journal of Advanced Research in Education Technology (IJARET), Vol. 1, Issue 1, July - Sept. (2014), pp. 11-17. available online: http://ijaret.com/wp-content/themes/felicity/issues/vollissue1/j_karthick-2.pdf.

[19] Sinan Abdulhkaleq, Yaseen, "Flexural Behavior of Self Compacting Concrete T-Beams Reinforced with AFRP", Eurasian Journal of Science \& Engineering, Vol. 4, Issue 2, December (2018), pp. 178-191, available online: https://doi.org/10.23918/eajse.v4i2p178.

[20] A. Buyukkaragoz, I. Kalkan, J. H. Lee, "A Numerical Study of the Flexural Behavior of Concrete Beams Reinforced with AFRP Bars", Strength of Materials Journal, Vol. 45(6), (2013), pp. 716-729, available online: https://doi.org/10.1007/s11223-013-9507-5.

[21] Mohamed Saafi, HoussamToutanji, "Flexural capacity of prestressed concrete beams reinforced with aramid fiber reinforced polymer (AFRP) rectangular tendons", Construction and Building Materials, Vol. 12, Issue 5, 1 July (1998), pp. 245-249, available online: https://doi.org/10.1016/S09500618(98)00016-6.

[22] Sinan Abdulhkaleq, Yaseen \& Muhammad Ali Ihsan, "Finite Element Modeling of High Strength Self-Compacting Concrete T Beams under Flexural Load Reinforced By ARFP" Eurasian Journal of Science \& Engineering, Vol. 4, Issue 4, June (2019), pp. 14-27, available online: https://doi: 10.23918/eajse.v4i4p14.

[23] R. Vidya Sagar, B.K. Raghu Prasad, "Damage limit states of reinforced concrete beams subjected to incremental cyclic loading using relaxation ratio analysis of AE parameters", Construction and Building Materials, Vol. 35, (2012), pp. 139-148, available online: https://doi.org/10.1016/i.conbuildmat.2012.02.057.

[24] F. K. Abdelsayed, M. H. Ahmed, K. H. Abdelkareem and M.H. Soghair, "Numerical Study of R.C. Bridge Beams under Static and Cyclic Loading", Journal of Engineering Sciences, Assiut University, Assiut, Egypt, Vol. 40, No. 1, January (2013), pp. 49-65, available online: http://www.aun.edu.eg/journal_files/135_J_6518.pdf. 